\title{
Study of Recycling Potential of FFP2 Face Masks and Characterization of the Plastic Mix-Material Obtained. A Way of Reducing Waste in Times of Covid-19
}

\author{
Cristina Crespo ${ }^{1}$ () $\cdot$ Gemma Ibarz $^{1} \cdot$ Carlos Sáenz $^{1} \cdot$ Pablo Gonzalez $^{1} \cdot$ Sandra $_{\text {Roche }}{ }^{1}$
}

Received: 11 December 2020 / Accepted: 19 May 2021 / Published online: 31 May 2021

(c) The Author(s), under exclusive licence to Springer Nature B.V. 2021

\begin{abstract}
The purpose of this study is to investigate how to recycle FFP2 face masks used during Covid-19 pandemic without using previous sorting process and to characterize the properties of the material obtained. The way of splitting and processing the mixture of materials was studied as well as the final properties such as chemical, thermal and mechanical characteristics. The resulting recycled material is a blend of polymers with such mechanical and thermal properties that could be used as an alternative to recycled PP (polypropylene). Avoidance of previous sorting process gives the face mask recycling a new and simplified way of preventing this material to be disposed in environment and an opportunity of second life for the polymers they are made of. With this work we lay the basis to reduce the plastic pollution related with the recommended use of face masks during Covid-19 pandemic.
\end{abstract}

\section{Graphic Abstract}
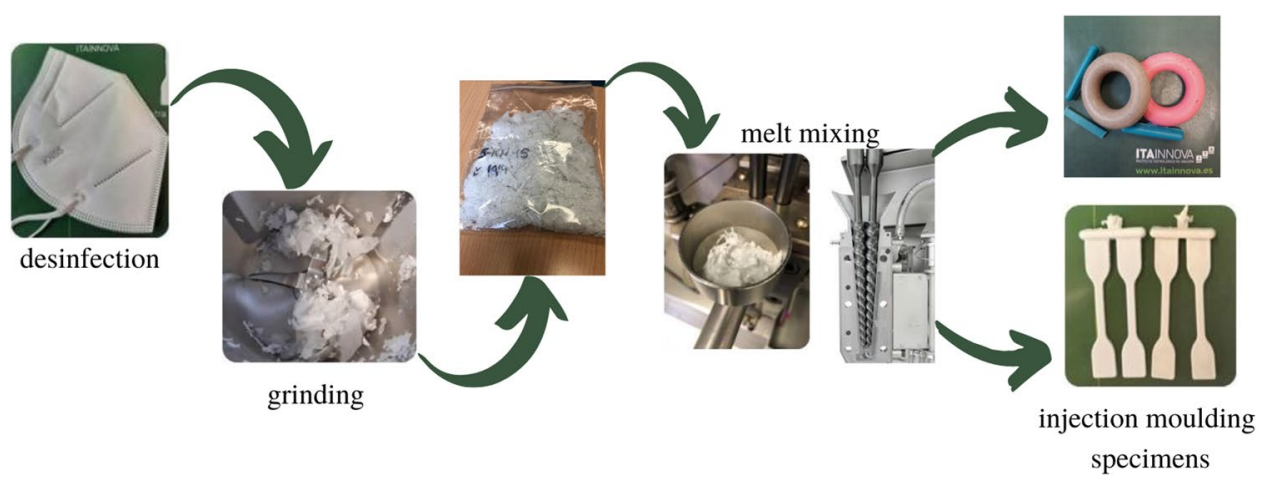

Keywords Recycling · Polypropylene $\cdot$ Face mask · Covid-19 - Waste recovery

\section{Statement of Novelty}

Face masks are treated as the raw material they are made of, that is polymer. Without sorting process and applying steps of mechanical recycling, a recycled material based of a mixing of three polymers is obtained. Four steps are

Cristina Crespo

ccrespo@itainnova.es needed: thermo chemical disinfection treatment, elimination of metal and ear strap, grinding, extrusion and injection. The mechanical properties of this material make it useful to obtain different products where recycled PP is being currently used, such as flower pots, storage bins or shipping pallets where technical specifications are not critical. With this methodology it would be possible to reduce the waste and contamination that those days of Covid-19 are generating.

1 Aragon Institute of Technology, María de Luna 7-8, 50018 Zaragoza, Spain 


\section{Introduction}

The pandemic situation of SARS-Covid-19 and the evidences that the spread of the virus is mainly related to the droplets and aerosols [1-3], in close proximity often speaking, coughing or sneezing, has led to the extensive use of face masks with the aim of stopping the massive infections. Several studies have already shown that the use of face masks could not only reduce the severity of the infection but also could help to cut down the options of transmission [4-6], of course this must not exclude the application of social distance.

Several models of face masks have been commercialized. The most widespread are the surgical ones which main purpose is to protect the community from infections that may be transmitted by the mask wearer, and the FFP2 [7, 8], where FFP2 stands for "Filtered Face Piece"; specially intended for protecting the wearer from inhalation of toxic particles or pathogens. These FFP2 face masks are able of filtering at least $94 \%$ of the air particles. Face masks effectiveness is related to the filter that stops respiratory droplets from getting through or around the device, and also related with the level of sealing, once it is adjusted to the face. Generally, FFP2 face mask has a structure of five layers of nonwoven material, where PP (polypropylene) and PE (polyethylene) are the basic materials for the filters layers and PA (polyamide) is used for the ear strap, while the nose wire is made of steel. Usually middle layers are embedded with an electrostatic charge that enhances the mechanical filtering efficiency [9]. There are variations in the product, depending on the manufacturer and also related to their final properties of filtration [10].

At this moment, where unfortunately the virus is spread worldwide and the use of face masks is extended as an easy way of protection and of slowing down the illness propagation, another environmental problem appears that has to be addressed. Face masks are considered as disposable. Making estimations and knowing that a mask weight is approximately $4 \mathrm{gr}$, in one year and taken into consideration that one quarter of the Spanish population could use one FFP2 mask per day; approximately 1.000 ton of plastic waste will be accumulated. Being aware of that situation will not be permanent, and thinking about the likelihood of using face mask will last one or two years, the number of plastic waste that will be generated in every country is more than significant. Furthermore, in hospitals and probably in other community centers, the use of this kind of protection will last.

Several options have been proposed in order to avoid plastic contamination due to face masks use during pandemic time: (1) use of alternative materials, (2) purification and reusability of face masks and (3) use of biodegradable materials.
As part of first option different household materials (commercial air filter fabric, cleaning cloth, coffee filter...) were proposed as alternatives materials for face masks fabrication $[11,12]$. In second case of purification and reusability, several investigations were conducting looking for alternatives of using several times the face masks after being disinfected. Juang [9] presents different methods of disinfection proposed by the inventor of KN95 material (equivalent to FFP2), that mainly consists in heating for $60 \mathrm{~min}$ at $70^{\circ} \mathrm{C}$. Other authors indicate more sophisticated methods for decontamination like an hydrogen peroxide vapor [13] or ultraviolet radiation, as explained by Mackenzie [14] among different options. The use of biodegradable materials is the third way of avoiding this facemask contamination [15]; in Spain, Spanish National Research Council has developed biodegradable antiviral filters based on nanofibers [16] that could be washed and reused for several times, that are commercialized nowadays by Bionicia Open Market; Geochanvre [17] a French company commercializes a full biodegradable mask based on natural fibers of hemp.

Certainly, disposable Protective Personal Equipment (PPE) has the disadvantage of generating a great impact on the environment, causing agglomeration of used masks in public space [18]. The impact of this PPE could be similar to other plastics, dumped in the environment: direct and indirect ingestion by the wildlife, causing respiratory and gastrointestinal obstructions or death by starvation, and the fundamental problem of strangulation. Fadere et al. [19] exposes the potential source of microplastics that face masks constitute. What it is clear is that Covid-19 has generated a number of different plastic residues that must be treated. Specific policies have to be developed in order to diminish this new way of contamination. H.B.Sharma et al. [20] exposed, that during this period; investigation related to the appropriate identification, collection, separation, disinfection and other tasks related with solid waste generated, has to be carried out in parallel with the virus treatment research. Battegazzore et al. [21] have recently presented different approaches for recycling surgical face mask; which are made of PP and does not present mixture of materials in the composition of the three layers of the faces masks; in this case they studied the option of including the ear loops made of fabric and elastomer. With this work we want to contribute to solve the problem of mixing different materials present at FFP2 as well as other option for waste reduction.

Thermoplastic recycling can be summarized in three different paths, mechanical, thermal and chemical [22]. The most extended one is the mechanical. However, nowadays chemical recycling for obtaining the initial monomers is taking more relevance [23], and it is considered as a good alternative to the mechanical process.

It is well known that the reuse of material in a production chain can be relatively easy because there is almost 
no opportunity for contamination. On the other hand, when talking about waste, whatever the origin is urban or postconsumer it appears a new difficulty due to the mixtures of polymers than can be found $[24,25]$.

The industrial process of recycling polymers includes a very important step of shortening and classification. One of the main points to have a successful polymer recycling process is the absence of mixtures of different polymers that can behave more like contaminants and impurities rather than reinforcement.

At this moment it is of great importance to investigate and develop alternatives to this new problem of plastic accumulation. First alternatives like valorization through thermal process [26] have been proposed. In this study we propose a new way of recycling the material of the face masks without any sorting or separation process. The FFP2 face masks are mainly made of PP and PE. Because the mixture of PP and $\mathrm{PE}$ is one of the most common that can be found in thermoplastic waste recovery, some studies have been carried out in order to improve the blending process and the final properties. One example in described by Fang et al. [27] with nanoparticles and compatibilizers or the study made by Clemons [28] where the blend is used to obtain wood plastic composites. Touati el al. [29], propose the use of diss fibers to obtain a reinforced recycled plastic of PP and PE.

The results shown in this paper aim to be a further step to find a second use of this new residue that generates a big impact in our environment. With this approach the investigation will continue by improving the properties of this new blend material but also with the way of the future steps for possible industrial use.

An additional option for waste and contamination reduction can be proposed if we think not about the product but in the thermoplastic based material of what they are made of. As thermoplastic polymers, they have the property of been melted and reused, and that is the aim of this study. In this work we propose a convenient and simple way of taking advantage of the polymer material that face masks are made of.

\section{Materials and Methods}

For the study of recyclability FFP2 face masks non used and used specimens were studied (Fig. 1). For the analysis of polymer composition of face masks, three different brands were studied, one for non used (Guangzhou Yibo Medical Technology), and other two different for used masks (Wuhu Koupin Protective Equipment Co from China. and Face Mask imported by Audix Bitee S.L.). In the packaging of non used face masks, indications of "protective mask UNE 149 and non-woven fabric" appear without material specifications.
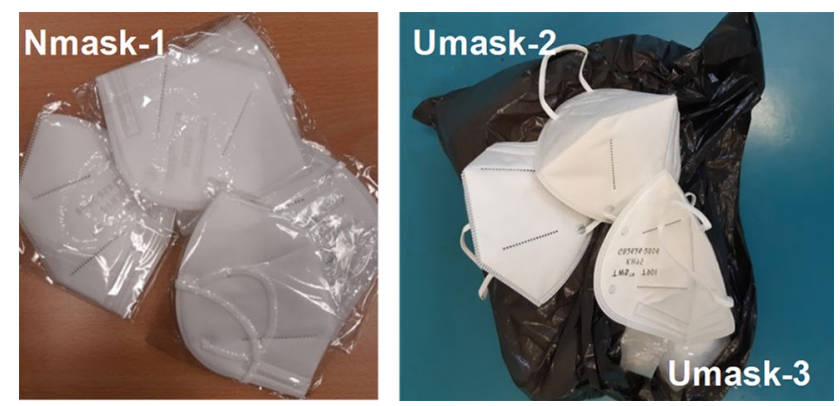

Fig. 1 Face masks used for analysis of polymer composition

For the compounding study of non used face masks, ten specimens of the same brand were selected; in this way initial material to be processed will be known. For the compounding study of the used face masks, ten specimens were collected from ITAINNOVA (Aragon Institute of Technology) employees. The used masks were collected from a specific waste bin, where the employees placed the mask after the labor day; in this way the process could be comparable to a hypothetical massive collection, where it will be not possible to separate according to brands, shape or color. In order to have a reference for the materials properties, recycled PP (rPP) kindly donated by Beologic in form of pellets and derived from different feedstock, was processed and analyzed. According to the supplier information, this rPP is suitable to produce garbage bins or flower pots among other applications. It has a density of $0.95 \mathrm{~g} / \mathrm{cm}^{3}$ and a melt flow index of $10 \mathrm{~g} / 10 \mathrm{~min}\left(230^{\circ} \mathrm{C}\right.$, $2.16 \mathrm{~kg}$ ) and no filler.

Used face masks recovered from employees of ITAINNOVA, were disinfected by using a mixed chemical-thermal treatment. The face masks were moistened for both sides with a ethanol $70 \%$ in volume of using a spray bottle and let them dry for one hour at $80{ }^{\circ} \mathrm{C}$ in a recirculated air oven. Once the face masks were at room temperature, the ear strap and the nose steel wires were removed with manual methods. Face masks were grinded with the help of a crusher.

Blending mix process was carried out by means of a micro twin extruder (DSM Xplorer model 2005) and materials specimens were obtained with a micro injector; from $\mathrm{X}$-plorer using a conical mould for tensile test samples. The injection molding was fed directly with the polymer melt from the extruder. Fig. 2 shows the above described steps.

Bone shape samples (ISO 527, sample 1B) were injected for the mechanical characterization. Five specimens for each sample were tested. Ten non used face masks were needed in order to obtain specimens for mechanical characterization, all of them from the same brand. Ten used face masks were taken from specific waste bin; in which different types and brands were mixed. Trying to emulate industrial collection no brand separation was done. Tensile 
Fig. 2 Mechanical recycling process

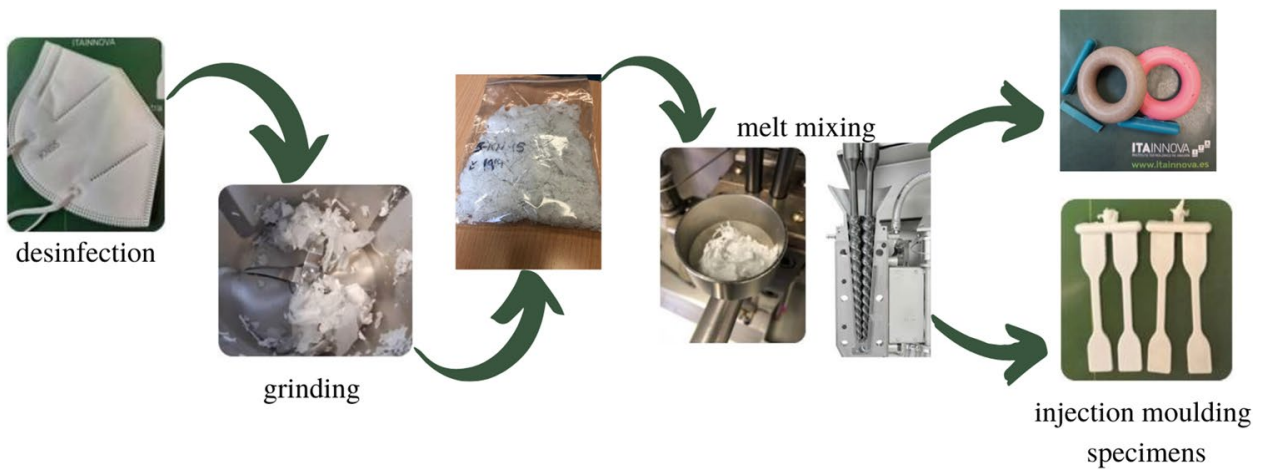

Table 1 Identification of face masks and materials used in the study

\begin{tabular}{ll}
\hline Reference & Face mask \\
\hline Nmask-1 & Non used face mask brand 1 \\
Umask-2 & Used face mask brand 2 \\
Umask-3 & Used face mask brand 3 \\
Reference & Material \\
pNmask & Processed Non used face masks \\
pUmask & Processed Used face mask \\
rPP & Recycled PP \\
\hline
\end{tabular}

Table 2 DSC analysis conditions

\begin{tabular}{lll}
\hline Step & & Conditions \\
\hline$\# 1$ & Isothermal & $10{ }^{\circ} \mathrm{C} 5$ min \\
$\# 2$ & Heating scan & From $10{ }^{\circ} \mathrm{C}$ to $280{ }^{\circ} \mathrm{C}$ at $10{ }^{\circ} \mathrm{C} / \mathrm{min}$ \\
$\# 3$ & Cooling scan & From $280{ }^{\circ} \mathrm{C}$ to $10^{\circ} \mathrm{C}$ at $10{ }^{\circ} \mathrm{C} / \mathrm{min}$ \\
$\# 4$ & Isothermal & $10{ }^{\circ} \mathrm{C} 5 \mathrm{~min}$ \\
$\# 6$ & Heating scan & From $10{ }^{\circ} \mathrm{C}$ to $280{ }^{\circ} \mathrm{C}$ at $10{ }^{\circ} \mathrm{C} / \mathrm{min}$ \\
\hline
\end{tabular}

tests were carried out at $23{ }^{\circ} \mathrm{C}$ and $50 \% \mathrm{RH}$ using Universal Testing Machine from Zwick Roell, according to international standards ISO 527.

Table 1 summarized the materials used in this study.

Spectrum Two from Perkin Elmer was utilized for ATRFTIR (Attenuated Total Reflectance-Fourier Transform Infrared) analysis of the layers of three different FFP2 brands face masks (see Table 1 for identification). The same equipment was used for the chemical analysis of the melt mixing material after extrusion process. For thermal analysis a differential scanning calorimeter (DSC) DSC-6 from Perkin Elmer was used following ISO 1137-2, (see Table 2 for test conditions). The density of the material after compounding was measured with a pycnometer following ISO 183 standard indications, at $23^{\circ} \mathrm{C}$ and using isopropanol as immersion medium; three replicates were measured for each sample. Thermal, chemical analysis of the melt mixing material after extrusion process, and density analysis were carried out with

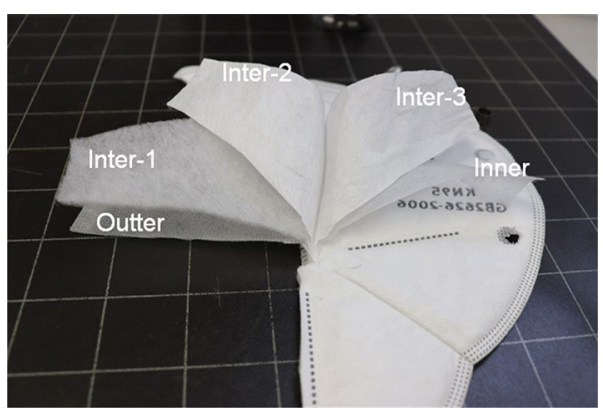

Fig. 3 Example of mask composition

a portion of material obtained from the samples of mechanical characterization.

\section{Results and Discussion}

\section{Analysis of Polymer Composition of Face Masks}

In order to know what kind of materials are in the layers that composed the face masks, three masks brands (Nmask-1, Umask-2 and Umask-3, Fig. 1) were analyzed by ATR-FTIR. The FTIR spectra of the different mask layers (see Fig. 3 as an example of layer composition) were obtained separately (Fig. 4) and analysis of the peaks was conducted in order to identify the main polymer that composed each layer. These results are summarized in Table 3 .

The assignments of the most representative peaks found in the spectra are summarized in Table 4. The FTIR spectrum of $\mathrm{PP}$ is dominated with several $\mathrm{CH}_{2} / \mathrm{CH}_{3}$ stretching vibration bands at around $2900 / \mathrm{cm}$ and the pair of $\mathrm{CH}_{2}$ bending/scissoring vibration bands at around $1400 / \mathrm{cm}$. In the FTIR spectrum of PE were found the same vibration bands, although it differ with PP in the number and relative intensity of these bands (e.g. while PP spectrum contains at least four vibration bands associated with the $\mathrm{CH}_{2} / \mathrm{CH}_{3}$ stretching, PE spectrum only contains two vibration bands associated with this mode of vibration). In addition, the FTIR spectrum 


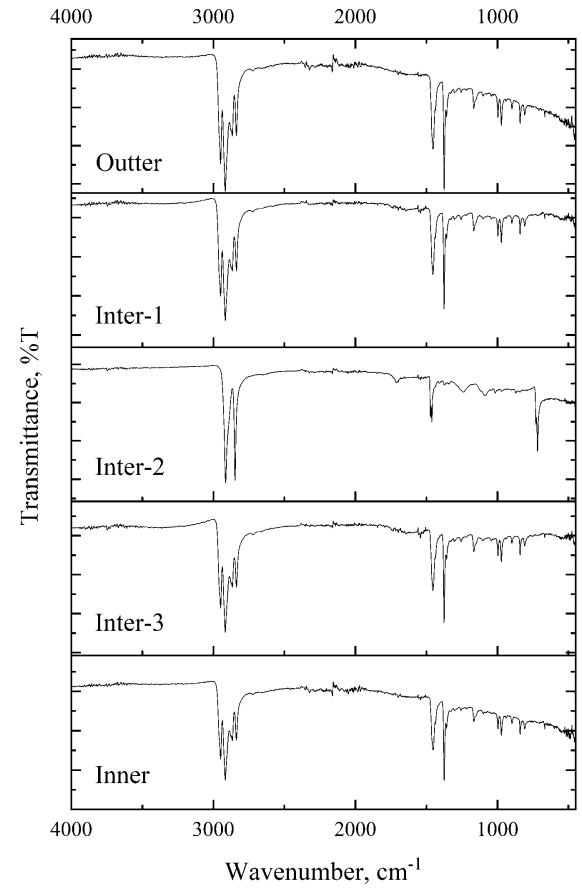

(a)

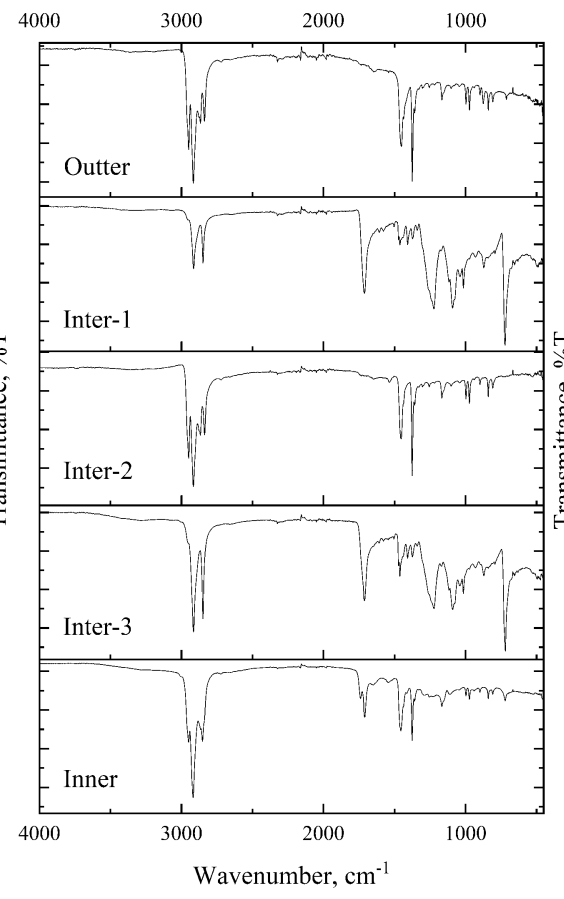

(b)

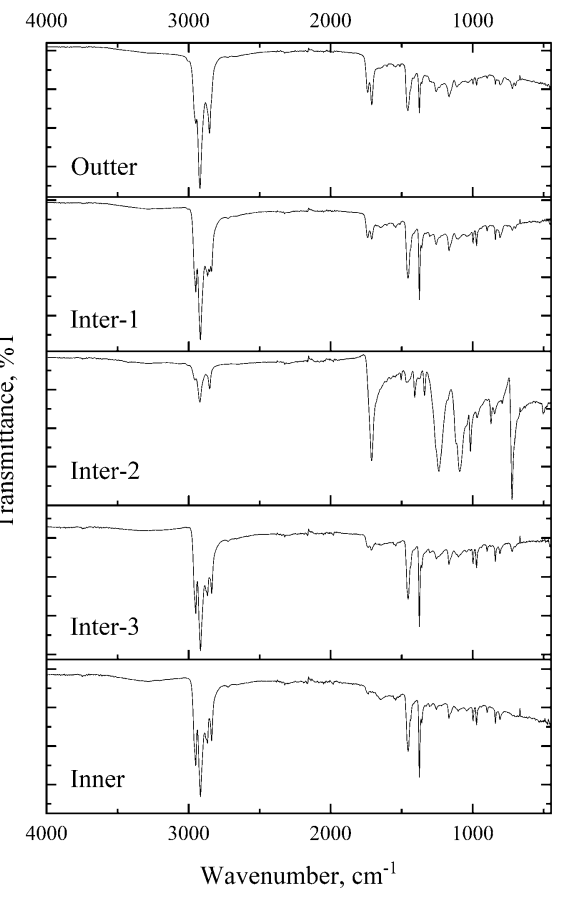

(c)

Fig. 4 ATR-FTIR spectra of face mask layers of a Nmask-1, b Umask-2 and c Umask-3

Table 3 FTIR analysis and identification of main polymer from FFP2 face masks layers

\begin{tabular}{llllll}
\hline & Outter & Inter-1 & Inter-2 & Inter-3 & Inner \\
\hline Nmask-1 & PP & PP & PE/PET & PP & PP \\
Umask-2 & PP & PET & PP & PE/PET & PP \\
Umask-3 & PP & PP & PET & PP & PP \\
\hline
\end{tabular}

of $\mathrm{PE}$ also contains the $\mathrm{CH}_{2}$ rocking vibration bands at $729 / 719 / \mathrm{cm}$. On the other hand, the FTIR spectrum of PET is mainly dominated by the bands associated with the vibration of the ester group $(-\mathrm{C}=\mathrm{O}(\mathrm{O}))$ located at 1713, 1238 and $1091 / \mathrm{cm}$. Considering these characteristics vibration bands of PP, PE and PET polymers, it was observed that the majority of the analyzed face mask layers were composed of a
Table 4 Assignments of the most representative peaks found in the spectra

\begin{tabular}{llll}
\hline Polymer & Wavenumber $\left(\mathrm{cm}^{-1}\right)$ & Description & Refs. \\
\hline PP & 2950 and 2865 & Assymm. and symm. $-\mathrm{CH}_{3}$ stretching & [30] \\
& 2920 and 2840 & Assymm. and symm. $-\mathrm{CH}_{2}$ stretching & \\
& 1453 and 1375 & Assymm. and symm. $-\mathrm{CH}_{3}$ bending (in plane) & \\
& 1165 & $-\mathrm{CH}_{3}$ wagging & \\
& 998 and 971 & $-\mathrm{CH}_{3}$ rocking & [31] \\
& 2914 and 2847 & Asymm. and symm. $-\mathrm{CH}_{2}$ stretching & \\
PE & 1471 & Assymm. $-\mathrm{CH}_{2}$ bending & [32] \\
& 1463 & $-\mathrm{CH}$ scissoring & [33] \\
& 729 and 719 & $-\mathrm{CH}$ rocking & \\
PET & 2921 and 2851 & Assymm. and symm. $-\mathrm{CH}_{2}$ stretching & \\
& 1713 & $\mathrm{C}=\mathrm{O}$ stretching & \\
& 1238 & $\mathrm{C}(=\mathrm{O})-\mathrm{O}$ stretching & \\
1091 & $\mathrm{C}-\mathrm{O}$ stretching & \\
& 1015 & Vibrations of aromatic ring & \\
& 722 & Ring $-\mathrm{CH}$ out of plane bending & \\
\hline
\end{tabular}


unique polymer, but in some cases (Inter-2 layer of Nmask-1 and Inter-3 layer of Umask-2) the FTIR spectrum indicated a blend of two PET and PE. Additional peaks were detected which were associated with additives whose identity is not the subject of the study.

\section{Compounding of Face Masks}

As it has been described above ten non used face masks and ten used faced masks were grinded and subsequently processed in a micro twin extruder, and then mould injected in order to obtain bone shape samples. See Table 5 for final process conditions of the material. The recycled polypropylene as reference is also included. Differences in process conditions are related with the mixtures of materials. As an example, the presence of PET increases the melt temperature needed for mould injection in comparison with the one needed for rPP.

The melting process conditions were selected taking into account the differences between individual fusion temperatures of the materials of the face mask. These values are in agreement with the ones used by Zang [34] studying the properties of recycled PET and PP at several conditions using the $240{ }^{\circ} \mathrm{C}$ among the temperature profile of the extruder and also the ones used by Mishra [35] who prepared blends of PET and PP. In our case we must consider that not only PP and PET are in the blend but also PE, therefore we chose $240{ }^{\circ} \mathrm{C}$ as a compromise for the melt mixing, avoiding to reach higher temperatures for avoiding PE and PP degradation.

Table 5 Polymer extrusion and injection conditions for bone shape samples

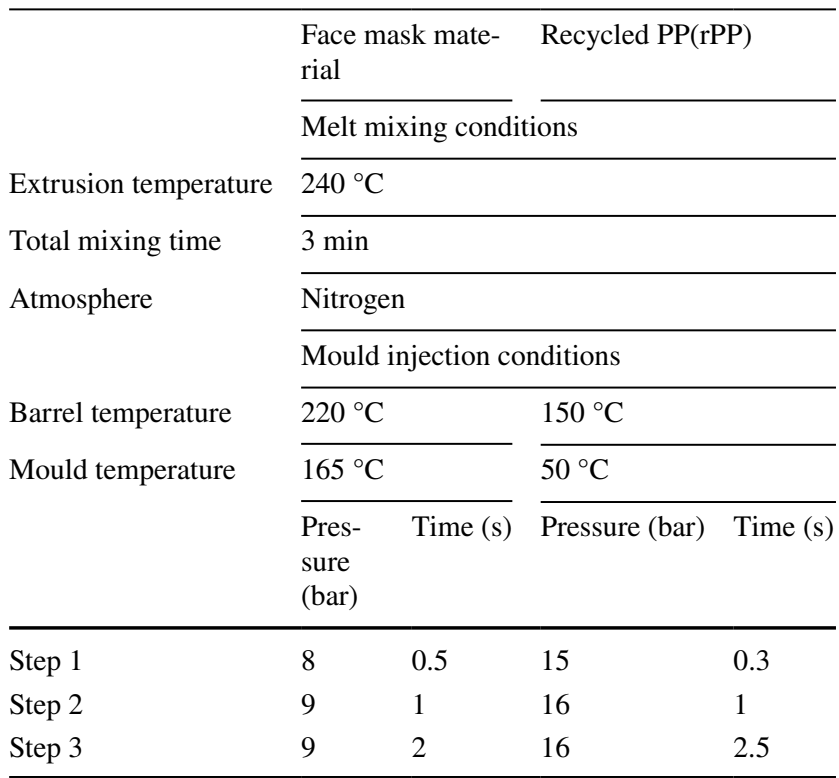
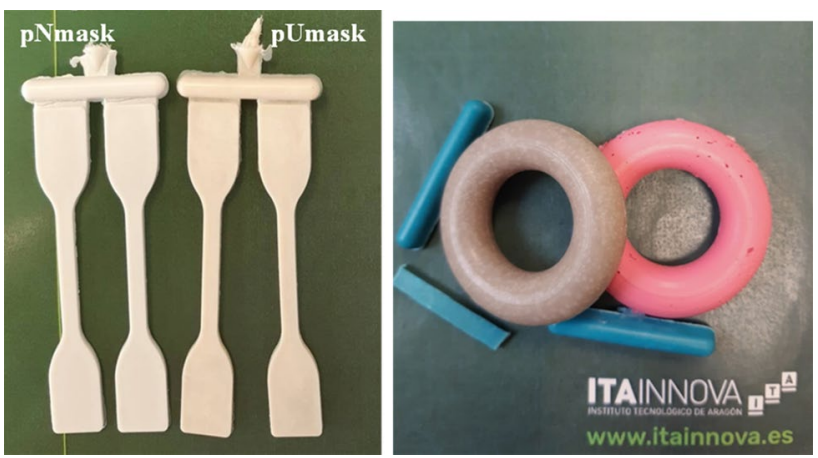

Fig. 5 Samples and products obtained with recycled material

Figure 5 shows samples obtained with the material from FFP2 face mask for mechanical characterization. Slightly color differences can be observed in samples pUmask obtained from the used face masks, that are darker, related probably with the mixtures of materials and possible contaminations due to the use of the face masks or degradation of polymers after the thermal process. In order to finally validate the recycling process, specific products ring shaped were obtained; these products are not for characterization but a final product for ornamental purposes.

\section{FTIR Analysis of Melt Blending Material}

With the aim of validating the melt mixing recycling process, the FTIR analysis of blending material (a portion of samples prepared for mechanical testing) was carried out; the spectra are shown in Fig. 6. It hast to be pointed out that pUmask material has been obtained from a mixture of different brands of face masks collected from a waste bin; that means that to compare this results with the ones of the non used mask (pNmask) will result in knowing the differences between materials as a global; not to know the possible degradation or changes suffered by the material masks for being used. Differences between samples in the FTIR spectra appeared mainly at the vibration bands located at around 1713, 1238 and 1091/, bands associated with the vibration of the ester group $(-\mathrm{C}=\mathrm{O}(\mathrm{O}))$ which were of more intensity in the pUmask sample in comparison with the other samples. As it was assigned in Table 4, these vibration bands are characteristic of PET polymers, whose presence was observed in the intermediate layers of the face masks. The presence of a very weak band at $1730 / \mathrm{cm}$ in the FTIR spectrum of rPP could be due to the existence of certain extent of degradation in this polymer associated to the formation of carbonyl groups [36, 37] 


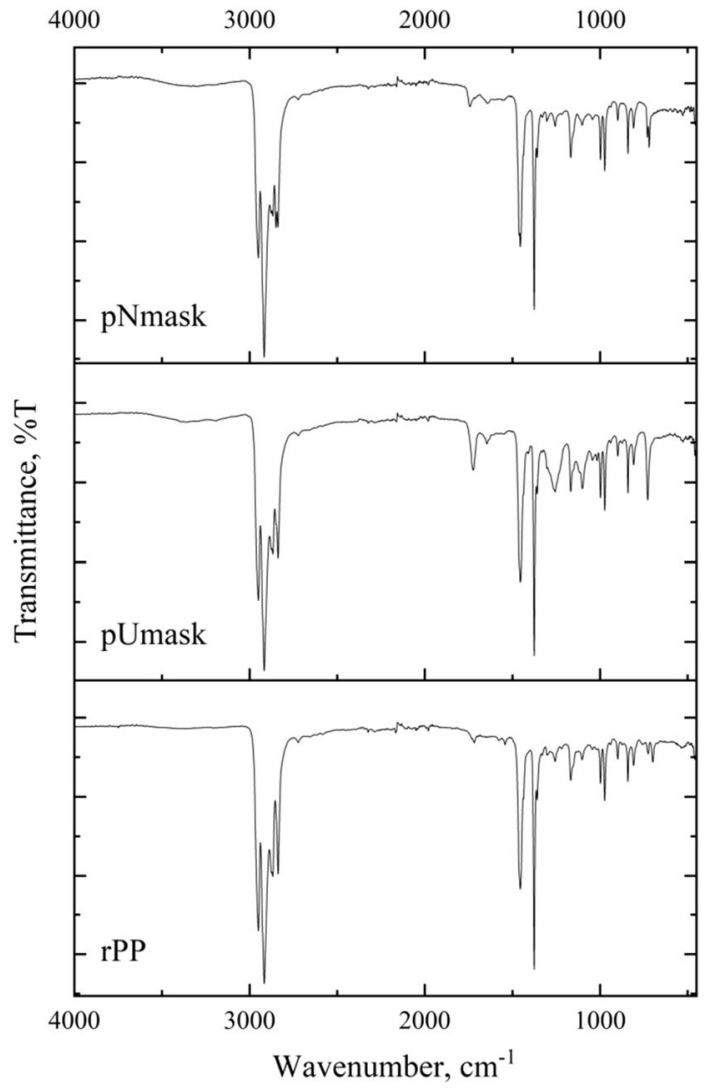

Fig. 6 ATR-FTIR spectra of face mask material, samples prepared for mechanical testing

Table 6 Enthalpy and peak temperature results at second heating DSC analysis

\begin{tabular}{|c|c|c|c|}
\hline \multicolumn{4}{|c|}{ Enthalpy $(\mathrm{kJ} / \mathrm{g})$ of $2^{\circ}$ heating } \\
\hline & $\Delta \mathrm{H}$ 1st peak () & $\Delta \mathrm{H} 2$ nd peak & $\Delta \mathrm{H} 3 \mathrm{rd}$ peak \\
\hline pNmask & 32.2 & 81.9 & 1.4 \\
\hline pUmask & 11.6 & 87.0 & 1.8 \\
\hline rPP & - & 95.4 & - \\
\hline \multicolumn{4}{|c|}{ Peak temperature $\left({ }^{\circ} \mathrm{C}\right)$ of $2^{\circ}$ heating } \\
\hline & $\mathrm{T}_{\text {peak }} 1$ st peak & $\mathrm{T}_{\text {peak }}$ 2nd peak & $\mathrm{T}_{\text {peak }} 3 \mathrm{rd}$ peak \\
\hline pNmask & 131.1 & 160.4 & 252.8 \\
\hline pUmask & 130.0 & 162.7 & 247.6 \\
\hline rPP & - & 164.4 & - \\
\hline
\end{tabular}

\section{Thermal Analysis}

Thermal analysis by DSC was carried out to verify the composition as well as thermal properties of the new blend. Table 6 presents the results obtained in thermal analysis in terms of enthalpy and peak temperature respectively at the second heating step, in Fig. 7 the thermograms curves are shown.

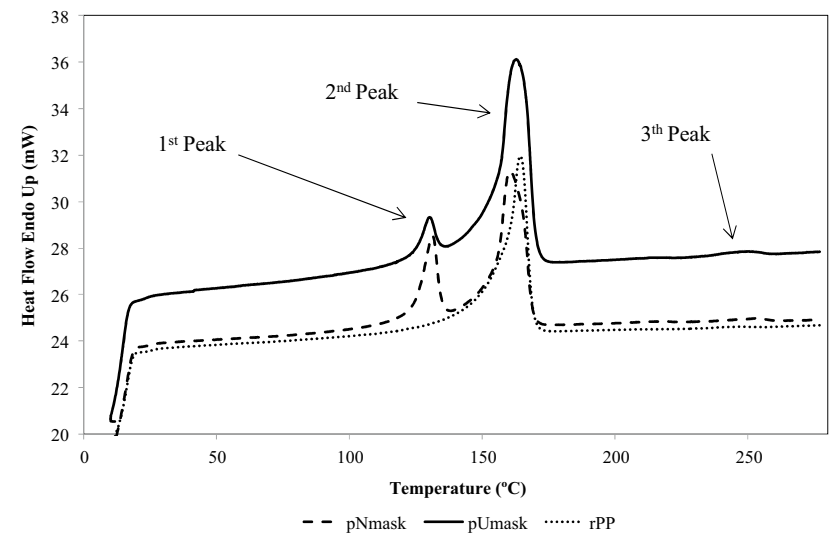

Fig. 7 DSC analysis of blended material

Table 7 Polymer presents according to DSC analysis

\begin{tabular}{llll}
\hline & \multicolumn{3}{l}{$\begin{array}{l}\text { Polymer present at } \\
\text { the blend }\end{array}$} \\
\cline { 2 - 4 } & PE & PP & PET \\
\hline pNmask & $\checkmark$ & $\checkmark$ & $\checkmark$ \\
pUmask & $\checkmark$ & $\checkmark$ & $\checkmark$ \\
rPP & × & $\checkmark$ & $\times$ \\
\hline
\end{tabular}

Table 8 Mechanical properties of blending material with confidence interval at $95 \%$

\begin{tabular}{lrll}
\hline & pNmask & pUmask & rPP \\
\hline Maximum Stress (MPa) & $23.6 \pm 0.2$ & $25 \pm 1$ & $32 \pm 3$ \\
Deformation at maximum stress (\%) & $7.2 \pm 0.4$ & $10 \pm 2$ & $9 \pm 0.4$ \\
Modulus (GPa) & $1.4 \pm 0.7$ & $1.4 \pm 0.3$ & $1.3 \pm 0.6$ \\
\hline
\end{tabular}

The melting points observed at the thermograms and their correlation with the fusion temperatures of pure polymers $\left(\mathrm{PE} \sim 130{ }^{\circ} \mathrm{C}, \mathrm{PP} \sim 160{ }^{\circ} \mathrm{C}\right.$ and $\mathrm{PET} \sim 250{ }^{\circ} \mathrm{C}$ ), corroborate that the new material from face masks is a blend where, PP is the main polymer and PE as well as PET are present in a less extent (Table 7).

\section{Density}

Density was measured as a basic property of the recycled material; pNmask material presents a density of $0.92 \mathrm{~g} / \mathrm{cm}^{3}$ while $0.99 \mathrm{~g} / \mathrm{cm}^{3}$ was the value for pUmask material, compared with the rPP of $0.96 \mathrm{~g} / \mathrm{cm}^{3}$. Those values are consistent with the properties of blending materials.

\section{Mechanical Properties}

Table 8 and Fig. 8 present the mechanical properties of the recycled materials. 
Fig. 8 Mechanical properties

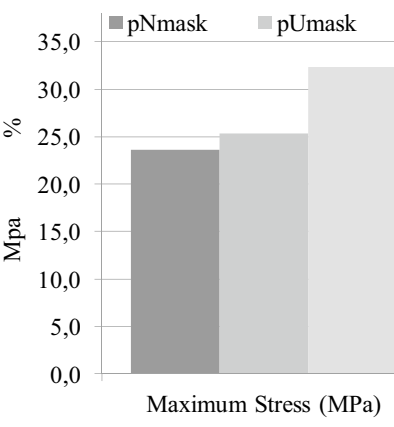

Maximum Stress (MPa)

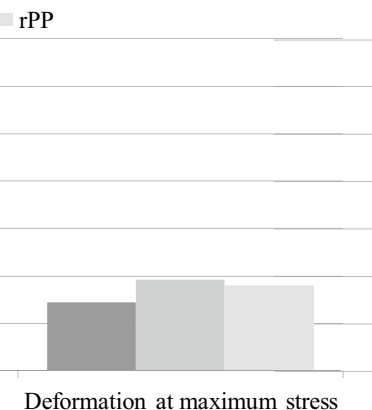

(\%)

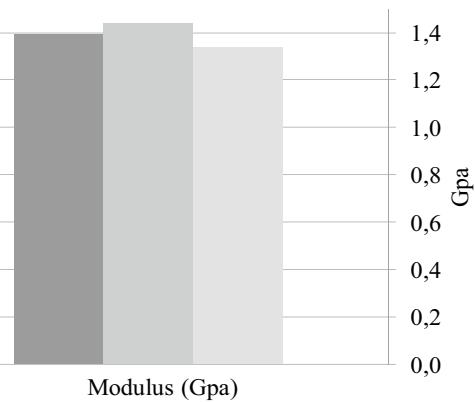

Modulus (Gpa)
0,0

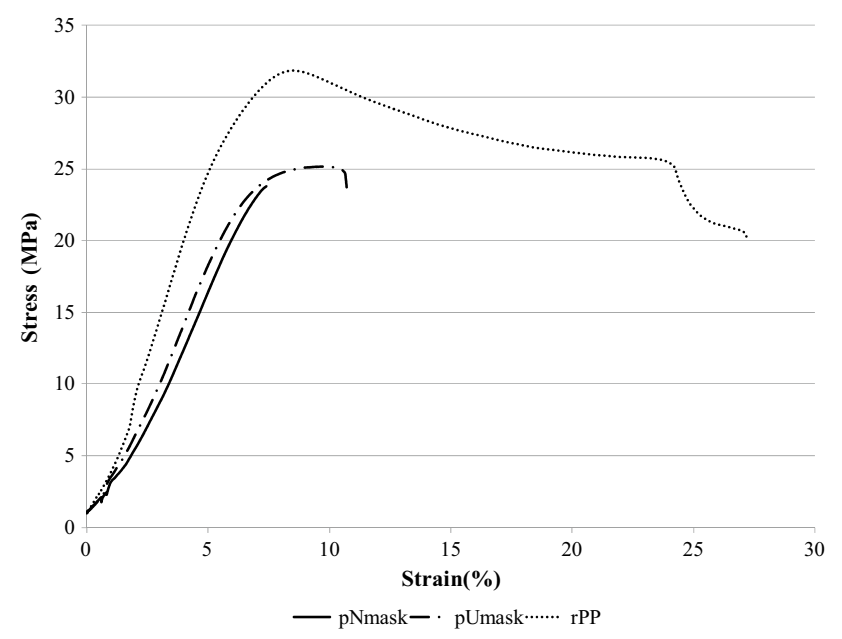

Fig. 9 Stress-strain curves

Comparable results in modulus have been obtained for the three materials. (pNmask, pUmask, rPP). rPP shows plastic deformation that reaches up to $25 \%$, which has not been visible in the samples of recycled mask material (Fig. 9) due to the mixture of the three polymers (PP, PE and PET).

The materials obtained from recycled face masks (pNmask and pUmask) show lower maximum stress and deformation compared to reference recycled PP. These properties are in accordance of reported results polymeric mixtures such as those from recycled PP of Strapasso et al. [38], in terms of stress and strain with a blend of PP and LDPE (Low Density Polyethylene) injected at $200{ }^{\circ} \mathrm{C}$ or the ones of E.G.Hanna of recycled polypropylene/polyethylene mixtures [39] taking into account that the presence of recycled PET could embrittle [40] the final mix and influence directly in the stress of the material. Comparing the results with the ones obtained by Battegazzore and coauthors [21], who studied the surgical face masks material, it can be noted that the overall mechanical properties of the recycled material from FFP2 masks are higher than the ones from the material from surgical masks. This can be explained taking into account the influence of the three materials present at FFP2 masks, and the amount of PET in the blending material could be the reason of the higher maximum stress and modulus.

The blending material of the three polymers that compose the face masks is assumed to be a different material from rPP. A point to be deeply studied in future is the possible existence of phases at micro structural level, something that can influence in the mechanical properties of the material as Zhang shows in his report [34]. In that sense, it also must be considered that the in the mechanical recycling the process of mixing materials could be improved with different compatibilizers [41] such as the case of thermoplastic elastomers [42], or maleic anhydride grafted polyethylene [27]. These studies of compatibilization are being explored by the authors in current studies.

\section{Conclusions}

In this study we have demonstrated that it is possible to recycle FFP2 face masks using the same protocols that are use in mechanical recycling of thermoplastic, in order to obtain a final blend of materials that can be processed in conventional equipment such as extruder and injection molding equipment. The material is a blend of PP, PE and PET and its thermal behavior presents three different melting points, in that way the conditions of processing at laboratory scale have been selected. Mechanical properties of the blend make it valid to obtain different products, such as flower pots, storage bins, shipping pallets or toys where technical specifications are not critical and can be an alternative to recycled PP.

This recycling process offers an interesting option for the utilization of the high amount of this solid waste that is being produced during Covid-19 pandemic and will contribute to reduce the plastic contamination. The fact of avoiding shortening and separation of different polymers can also contribute to the recycling process in an economic way. Authors plan to continue with this research to complete the characterization and increase the properties of the blending material where compatibilization and additives will be evaluated in order to increase final properties. 
Acknowledgements Publication developed in the framework of ITA01_04_Proyectos de Capacitación Tecnológica-Programa Operativo FSE Aragón 2014-2020, Fondo Social Europeo, Construyendo Europa desde Aragón".The authors want to thank you all the Design and Development Materials Technology of ITAINNOVA who in some way participate and encourage the realization of this work.

Author Contributions CC: Supervision, Conceptualization, Methodology, Writing- Reviewing and Editing. GI: Writing- Reviewing and Editing. PG: Formal analysis, Reviewing. CS: Investigation, Data review, Formal analysis. SR: Investigation, Data review, Formal analysis.

Funding Publication developed in the framework of ITA01_04_ Proyectos de Capacitación Tecnológica - Programa Operativo FSE Aragón 2014-2020, Fondo Social Europeo, Construyendo Europa desde Aragón.

\section{References}

1. Zhao, L., Qi, Y., Luzzatto-Fegiz, P., Cui, Y., Zhu, Y.: COVID-19: effects of environmental conditions on the propagation of respiratory droplets. Nano Lett (2020). https://doi.org/10.1021/acs.nanol ett.0c03331

2. Van Doremalen, N., Bushmaker, T., Morris, D.H., Holbrook, M.G., Gamble, A., Williamson, B.N., Tamin, A., Harcourt, J.L., Thornburg, N.J., Gerber, S.I., Lloyd-Smith, J.O.: Aerosol and surface stability of SARS-CoV-2 as compared with SARS-CoV-1. New Engl. J. Med. 382(16), 1564-1567 (2020)

3. Zhang, R., Li, Y., Zhang, A.L., Wang, Y., Molina, M.J.: Identifying airborne transmission as the dominant route for the spread of COVID-19. PNAS 117, 14857-14863 (2020). https://doi.org/10. 1073/pnas.2009637117

4. Peeples, L.: Face masks: what the data say. Nature 586, 186-189 (2020). https://doi.org/10.1038/d41586-020-02801-8

5. Howarda, J., Austin Huangb, Z.L., Tufekcim, Z., Vladimire, Z., van der Westhuizenf, H.M., von Delfto, A., Rimoint, A.W.: Face masks against COVID-19: an evidence. Review (2020). https:// doi.org/10.20944/preprints202004.0203.v1

6. Gandhi, M., Beyrer, C., Goosby, E.: Masks do more than protect others during COVID-19: reducing the inoculum of SARS-CoV-2 to protect the wearer. J. Gen. Intern. Med. 35, 3063-3066 (2020). https://doi.org/10.1007/s11606-020-06067-8

7. EN 143:2000, Respiratory Protective Devices - Particle Filters Requirements, Testing, Marking

8. EN 149:2001+A1:2009 Respiratory Protective Devices—Filtering Half Masks to Protect against Particles—Requirements, Testing, Marking

9. Juang, P.S.C., Tsai, P.: N95 respirator cleaning and reuse methods proposed by the inventor of the N95 mask material. J. Emerg. Med. 58, 817-820 (2020). https://doi.org/10.1016/j.jemermed. 2020.04.036

10. Leonas, K.K., Jones, C.R., Hall, D.: The relationship of fabric properties and bacterial filtration efficiency for selected surgical face masks. JTATM 3, 1-8 (2003)

11. Mueller, A.V., Eden, M.J., Oakes, J.M., Bellini, C., Fernandez, L.A.: Quantitative method for comparative assessment of particle removal efficiency of fabric masks as alternatives to standard surgical masks for PPE. Matter 3(3), 950-962 (2020)

12. Teesing, G.R., van Straten, B., de Man, P., Horeman-Franse, T.: Is there an adequate alternative to commercially manufactured face masks? A comparison of various materials and forms. J. Hosp. Infect. 106, 246-253 (2020). https://doi.org/10.1016/j.jhin.2020. 07.024
13. Schwartz, A., Stiegel, M., Greeson, N., Vogel, A., Thomann, W., Brown, M., Sempowski, G.D., Alderman, T.S., Condreay, J.P., Burch, J., et al.: Decontamination and reuse of N95 respirators with hydrogen peroxide vapor to address worldwide personal protective equipment shortages during the SARS-CoV-2 (COVID19) pandemic. Appl. Biosaf. 25, 67-70 (2020). https://doi.org/10. $1177 / 1535676020919932$

14. Mackenzie, D.: Reuse of N95 masks. Engineering 6, 593-596 (2020). https://doi.org/10.1016/j.eng.2020.04.003

15. Das, O., Neisiany, R.E., Capezza, A.J., Hedenqvist, M.S., Försth, M., Xu, Q., Jiang, L., Ji, D., Ramakrishna, S.: The need for fully bio-based facemasks to counter coronavirus outbreaks: a perspective. Sci. Total Environ. 736, 139611 (2020). https://doi.org/10. 1016/j.scitotenv.2020.139611

16. CSIC Llegan al mercado las mascarillas sanitarias con nanofibras desarrolladas por el CSIC Available online: https://www.csic.es/ (Accessed on 27 November 2020)

17. Masque Biocompostable $100 \%$ Made in France Available online: https://www.geochanvre.fr/masque/ (Accessed on 27 November 2020)

18. Adyel, T.M.: Accumulation of plastic waste during COVID-19. Science 369, 1314-1315 (2020). https://doi.org/10.1126/science. abd 9925

19. Fadare, O.O., Okoffo, E.D.: Covid-19 face masks: a potential source of microplastic fibers in the environment. The Sci. Total Environ. 737, 140279 (2020). https://doi.org/10.1016/j.scitotenv. 2020.140279

20. Sharma, H.B., Vanapalli, K.R., Cheela, V.S., Ranjan, V.P., Jaglan, A.K., Dubey, B., Goel, S., Bhattacharya, J.: Challenges, opportunities, and innovations for effective solid waste management during and post COVID-19 pandemic. Resour. Conserv. Recycl. 162, 105052 (2020). https://doi.org/10.1016/j.resconrec.2020.105052

21. Battegazzore, D., Cravero, F., Frache, A.: Is It possible to mechanical recycle the materials of the disposable filtering masks? Polymers 12, 2726 (2020). https://doi.org/10.3390/polym12112726

22. Vollmer, I., Jenks, M.J., Roelands, M.C., White, R.J., van Harmelen, T., de Wild, P., van Der Laan, G.P., Meirer, F., Keurentjes, J.T., Weckhuysen, B.M.: Beyond Mechanical Recycling: Giving New Life to Plastic Waste. Angew. Chem, Int. Ed. 59, 1540215423 (2020). https://doi.org/10.1002/anie.201915651

23. Braido, R.S., Borges, L.E.P., Pinto, J.C.: Chemical recycling of crosslinked poly(Methyl Methacrylate) and characterization of polymers produced with the recycled monomer. J. Anal. Appl. Pyrol. 132, 47-55 (2018). https://doi.org/10.1016/j.jaap.2018.03. 017

24. Al-Salem, S.M., Lettieri, P., Baeyens, J.: Recycling and recovery routes of plastic solid waste (PSW): a review. Waste Manage. 29, 2625-2643 (2009). https://doi.org/10.1016/j.wasman.2009.06.004

25. Hamad, K., Kaseem, M., Deri, F.: Recycling of waste from polymer materials: an overview of the recent works. Polym. Degrad. Stab. 98, 2801-2812 (2013). https://doi.org/10.1016/j.polymdegra dstab.2013.09.025

26. Jung, S., Lee, S., Dou, X., Kwon, E.E.: Valorization of disposable COVID-19 mask through the thermo-chemical process. Chem. Eng. J. 405, 126658 (2021). https://doi.org/10.1016/j.cej.2020. 126658

27. Fang, C., Nie, L., Liu, S., Yu, R., An, N., Li, S.: Characterization of polypropylene-polyethylene blends made of waste materials with compatibilizer and nano-filler. Compos. B Eng. 55, 498-505 (2013). https://doi.org/10.1016/j.compositesb.2013.06.046

28. Clemons, C.: Elastomer modified polypropylene-polyethylene blends as matrices for wood flour-plastic composites. Compos. A Appl. Sci. Manuf. 41, 1559-1569 (2010). https://doi.org/10. 1016/j.compositesa.2010.07.002

29. Touati, Z., Boulahia, H., Belhaneche-Bensemra, N., Massardier, V.: Modification of diss fibers for biocomposites based on 
recycled low-density polyethylene and polypropylene blends. Waste Biomass Valor 10, 2365-2378 (2019). https://doi.org/10. 1007/s12649-018-0225-x

30. McDonald, M.P., Ward, I.M.: The assignment of the infra-red absorption bands and the measurement of tacticity in polypropylene. Polymer 2, 341-355 (1961). https://doi.org/10.1016/00323861(61)90037-4

31. Charles, J., Ramkumaar, G.R.: Qualitative analysis of high density polyethylene using FTIR spectroscopy. Asian J. Chem. 21, 8 (2009)

32. Liang, C.Y., Krimm, S.: Infrared spectra of high polymers: Part IX. Polyethylene terephthalate. J. Mol. Spectrosc. 3(1-6), 554574 (1959)

33. Dave, H., Ledwani, L., Chandwani, N., Kikani, P., Desai, B., Nema, S.K.: Surface modification of polyester fabric by nonthermal plasma treatment and its effect on coloration using natural dye. J. Polym. Mater. 30(3), 14 (2013)

34. Zhang, Z., Wang, C., Mai, K.: Reinforcement of recycled PET for mechanical properties of isotactic polypropylene. Adv. Ind. Eng. Polym. Res. 2, 69-76 (2019). https://doi.org/10.1016/j.aiepr.2019. 02.001

35. Mishra, R.K., Mishra, P., Verma, K., Joseph, K.: Manipulation of thermo-mechanical, morphological and electrical properties of PP/PET polymer blend using MWCNT as nano compatibilizer: a comprehensive study of hybrid nanocomposites. Vacuum 157, 433-441 (2018). https://doi.org/10.1016/j.vacuum.2018.08.061

36. Almond, J., Sugumaar, P., Wenzel, M.N., Hill, G., Wallis, C.: Determination of the carbonyl index of polyethylene and polypropylene using specified area under band methodology with ATRFTIR spectroscopy. E-Polymers 20, 369-381 (2020). https://doi. org/10.1515/epoly-2020-0041
37. Longo, C., Savaris, M., Zeni, M., Brandalise, R.N., Grisa, A.M.C.: Degradation study of polypropylene (PP) and bioriented polypropylene (BOPP) in the environment. Mat. Res. 14, 442-448 (2011). https://doi.org/10.1590/S1516-14392011005000080

38. Strapasson, R., Amico, S.C., Pereira, M.F.R., Sydenstricker, T.H.D.: Tensile and impact behavior of polypropylene/low density polyethylene blends. Polym. Test. 24, 468-473 (2005). https://doi. org/10.1016/j.polymertesting.2005.01.001

39. Hanna, E.G.: Recycling of waste mixed plastics blends (PE/PP). JESTR 12, 87-92 (2019). https://doi.org/10.25103/jestr.122.12

40. Imamura, N., Sakamoto, H., Higuchi, Y., Yamamoto, H., Kawasaki, S., Yamada, K., Nishimura, H., Nishino, T.: Effectiveness of compatibilizer on mechanical properties of recycled PET blends with PE, PP, and PS. Mater. Sci. Appl. 5, 548-555 (2014). https:// doi.org/10.4236/msa.2014.58057

41. Maris, J., Bourdon, S., Brossard, J.-M., Cauret, L., Fontaine, L., Montembault, V.: Mechanical recycling: compatibilization of mixed thermoplastic wastes. Polym. Degrad. Stab. 147, 245-266 (2018). https://doi.org/10.1016/j.polymdegradstab.2017.11.001

42. Matei, E., Râpă, M., Andras, Á.A., Predescu, A.M., Pantilimon, C., Pica, A., Predescu, C.: Recycled polypropylene improved with thermoplastic elastomers. Int. J. Polym. Sci. 2017, e7525923 (2017). https://doi.org/10.1155/2017/7525923

Publisher's Note Springer Nature remains neutral with regard to jurisdictional claims in published maps and institutional affiliations. 